\title{
Sulphur dioxide sensitivity and plasma antioxidants in adult subjects with asthma
}

\author{
Carol A Trenga, Jane Q Koenig, Paul V Williams
}

\begin{abstract}
Objectives-To screen adult subjects with asthma for sensitivity to inhaled sulphur dioxide $\left(\mathrm{SO}_{2}\right)$ and identify subject characteristics associated with that sensitivity. Medication use, symptoms, and plasma antioxidant nutrients between $\mathrm{SO}_{2}$ responders and non-responders were compared.
\end{abstract}

Methods-Adult subjects (ages 18-39 years) with asthma were exposed to 0.5 ppm $\mathrm{SO}_{2}$ for 10 minutes during moderate exercise. Pulmonary function tests and symptom ratings were assessed before and after exposure $(n=47)$. A subject was classified as sensitive to $\mathrm{SO}_{2}$ if forced expiratory volume in 1 second $\left(F E V_{1}\right)$ showed a drop $\geqslant 8 \%$ over baseline. Blood samples were obtained from subjects $(n=38)$ before the $\mathrm{SO}_{2}$ challenge; plasma ascorbate, $\alpha$-tocopherol, retinol, carotenoids, and lipids were measured.

Results-Of the 47 subjects screened, $53 \%$ had a drop in $\mathrm{FEV}_{1} \geqslant 8 \%$ (ranging from $-8 \%$ to $-44 \%)$. Among those 25 subjects, the mean drop in $\mathrm{FEV}_{1}$ was $-17.2 \%$. Baseline pulmonary function indices $\left(\mathrm{FEV}_{1} \%\right.$ of predicted and $\mathrm{FEV}_{1} / \mathrm{FVC} \%$ (forced vital capacity)) did not predict sensitivity to $\mathrm{SO}_{2}$. Although use of medication was inversely related to changes in pulmonary function after $\mathrm{SO}_{2}(p<0.05)$, both $\mathrm{SO}_{2}$ responders and non-responders were represented in each medication category. Total symptom scores after exposure were significantly correlated with changes in $\mathbf{F E V}_{1}$ $(p<0.05)$, FVC $(p<0.05)$, and peak expiratory flow $(\mathrm{PEF})(\mathrm{p}<0.01)$ but not forced expiratory flow between $25 \%$ and $75 \%$ vital capacity $\left(\mathrm{FEF}_{25-75}\right)$. Plasma $\boldsymbol{\beta}$-carotene concentrations were inversely associated with PEF values and ascorbate concentrations were inversely associated with $\mathrm{FEV}_{1}$ and $\mathrm{FEV}_{1} / \mathrm{FVC}$ ( $\mathrm{p}=\mathbf{0 . 0 5}$ in all cases). High density lipoprotein concentrations were positively correlated with $\mathrm{FEV}_{1} \%$ of predicted $(p<0.05)$ and inversely correlated with change in $\mathrm{FEF}_{25-75}(\mathbf{p}<0.05)$ after $\mathrm{SO}_{2}$. Conclusion-These results show that the response to $\mathrm{SO}_{2}$ among adults with mild to moderate asthma is very diverse. Severity of asthma defined by medication category was not a predictor of sensitivity to $\mathrm{SO}_{2}$. Lung function values were associated with $\beta$-carotene and ascorbate concentrations in plasma; however, plasma antioxidant nutrient concentrations were not associated with sensitivity to inhaled $\mathrm{SO}_{2}$. (Occup Environ Med 1999;56:544-547)
Keywords: asthma; sensitivity; antioxidants

Sulphur dioxide $\left(\mathrm{SO}_{2}\right)$ is a common ambient and occupational air pollutant. Sources of $\mathrm{SO}_{2}$ include electric coal fired power plants, smelters, wood pulp manufacturing, and food processing operations. ${ }^{1}$ It is one of six common outdoor air pollutants regulated as criteria pollutants by the United States Environmental Protection Agency. About 600000 workers in the United States are exposed to $\mathrm{SO}_{2}$ at work. ${ }^{2}$ The typical responses to inhaled $\mathrm{SO}_{2}$ in subjects with asthma are acute bronchoconstriction measured as decrements in forced expiratory volume in one second $\left(\mathrm{FEV}_{1}\right)$ or increases in airway resistance. ${ }^{34}$ Subjects with asthma have significant changes in pulmonary function after brief exposures at concentrations as low as $0.25 \mathrm{ppm}$ whereas subjects without asthma often have no significant change in pulmonary function after exposures below $5 \mathrm{ppm} .^{5}$ A recent report determined the prevalence of airway hyperresponsiveness to $\mathrm{SO}_{2}$ in an adult population of 790 subjects, aged $20-44$ years, as part of the European Community respiratory health survey. The prevalence of $\mathrm{SO}_{2}$ hyperresponsiveness (measured as a $20 \%$ decrease in $\mathrm{FEV}_{1}$ ) in that population was $3.4 \% .^{6}$ Of subjects with a methacholine positive response, $22 \%$ showed sensitivity to $\mathrm{SO}_{2}$ whereas only two out of 679 who were not methacholine positive had such sensitivity, although the presence of asthma was not used directly as a risk factor.

Concentrations of vitamins E ( $\alpha$ tocopherol), C (ascorbate), A (retinol), and carotenoids in peripheral blood may be useful biomarkers for predicting the response of adults with asthma to air pollutants. Epidemiological studies have shown a relation between dietary concentrations of vitamin $\mathrm{C}$ and pulmonary function values. ${ }^{7-10}$ There is evidence that vitamin $C$ intake in the general population is correlated with asthma status and that people with asthma have lower serum vitamin C than people without. ${ }^{11}$ Low dietary intake of vitamins $\mathrm{C}^{12}$ and $\mathrm{E}^{13}$ are associated with an increased risk of developing asthma. Plasma concentrations of antioxidant vitamins do not always show a good correlation with dietary intake, particularly for lipid soluble antioxidants such as $\alpha$-tocopherol and $\beta$-carotene. However, they serve as good markers of internal dose, as factors other than diet-such as variations in absorption and metabolism-are reflected in plasma concentrations. ${ }^{14} 15$

This paper describes the responses of adult subjects with asthma to a 10 minute $\mathrm{SO}_{2}$ 
screening test. The relation between response to $\mathrm{SO}_{2}$ exposure, medication, symptoms, and plasma antioxidant nutrients are discussed.

\section{Methods}

The use of human subjects was approved by the University of Washington Human Subjects Committee. Subjects with a history of asthma aged 18-39 years were recruited from local asthma and allergy clinics, university students, faculty, and staff, and the general population. Forty seven subjects (14 men and 33 women) completed the screening procedure. Use of medication was restricted as follows: use of long acting and short acting $\beta_{2}$ agonist was prohibited within 12 and 6 hours of the screening visit, respectively. Inhaled antiinflammatory medications were withheld on the screening day.

Subjects inhaled $\mathrm{SO}_{2}$ by a mouthpiece while wearing noseclips for 10 minutes during moderate exercise on a treadmill. The treadmill was set to achieve about a threefold increase in resting minute ventilation. Minute ventilation was measured continuously during each challenge test. The $\mathrm{SO}_{2}$ was generated in a gas aerosol generation and monitoring system connected to the mouthpiece described earlier. ${ }^{16}$

Pulmonary function $\left(\mathrm{FEV}_{1}\right.$, forced vital capacity (FVC), forced expiratory flow between $25 \%$ and $75 \%$ vital capacity $\left(\mathrm{FEF}_{25-75}\right)$ ) was measured with a computerised spirometer (Spirometrics III) according to American Thoracic Society guidelines. Peak expiratory flow (PEF) was measured with a hand held peak flow meter (Vitalograph). Pulmonary function was measured before and within 10 minutes after the $\mathrm{SO}_{2}$ challenge. An $8 \%$ drop in $\mathrm{FEV}_{1}$, based on previous studies, ${ }^{16}{ }^{17}$ was chosen as the criterion for categorising subjects as $\mathrm{SO}_{2}$ responders. Subjects completed a symptom rating form before and after the exposure. Ten symptoms were rated from $0=$ none to $5=$ severe, grouped as follows: upper respiratory (nasal discharge, sore throat), lower respiratory (cough, chest pain or burning, dyspnoea, wheeze), and other (headache, fatigue, unusual smell or taste, dizziness).

Non-fasting blood samples were drawn from each subject at the beginning of the screening visit. Plasma ascorbate, $\alpha$-tocopherol, retinol, carotenoids, and lipids (total cholesterol, high density lipoprotein (HDL) cholesterol, low density lipoprotein (LDL) cholesterol, and triglycerides) were measured. Samples were analysed by the Clinical Nutrition Research Unit at the University of Washington. Plasma concentrations of ascorbic acid were measured enzymatically with a Cobas-Bio centrifugal

Table 1 Mean (SD) subject characteristics and $\mathrm{SO}_{2}$ response by category of medication

\begin{tabular}{llllll}
\hline $\begin{array}{l}\text { Medication } \\
\text { category }\end{array}$ & $\begin{array}{l}\text { Age } \\
\text { (mean, } y)\end{array}$ & $n$ & $\begin{array}{l}\text { FEV \% of } \\
\text { predictedt }\end{array}$ & FEV $/ F V C \%+$ & $\begin{array}{l}\text { SO response } \\
\left.\text { (\% change FEV } V_{\nu}\right)\end{array}$ \\
\hline 1 & 24.4 & 11 & $101.5(16.5)$ & $78.1(10.3)$ & $-3.4(4.8)$ \\
2 & 26.5 & 15 & $100.3(14.6)$ & $90.0(6.0)$ & $-7.8(6.0)$ \\
3 & 24.3 & 12 & $91.7(13.3)$ & $75.7(8.4)$ & $-13.3(13.9)$ \\
4 & 26.6 & 9 & $84.6(9.7)$ & $75.7(9.3)$ & $-17.6(15.1)$ \\
\hline
\end{tabular}

${ }^{\star} 1=$ no regular medication; $2=$ bronchodilator when necessary; $3=$ daily bronchodilator; $4=$ bronchodilator+anti-inflammatory.

†Calculated from prescreening best $\mathrm{FEV}_{1}$, and best $\mathrm{FVC}$ for $\mathrm{FEV}_{1} / \mathrm{FVC} \%$. analysis. ${ }^{18}$ Carotenoids, ${ }^{19}$ retinol, and $\alpha$-tocopherol were extracted from plasma in a total lipid fraction and measured by high performance liquid chromatography. ${ }^{20}$ A lipid profile was produced by standard clinical laboratory techniques.

Statistical analyses were conducted with the SPSS software package. Changes in pulmonary function changes by medication category were examined by analysis of variance (ANOVA) and a Bonferroni test to compare group means. Significance was set at $\mathrm{p}=0.05$. Associations between medication category and pulmonary function change were measured by Spearman's correlation coefficients (one tailed). Paired $t$ tests compared symptom scores before and after $\mathrm{SO}_{2}$ challenge. Independent sample $t$ tests were used to compare symptom scores by $\mathrm{SO}_{2}$ response groups. Plasma nutrient and pulmonary function partial correlations were adjusted for age, race, and sex. Analysis of varience tests were applied to selected plasma variables (ascorbate, retinol, $\beta$-carotene, lycopene) to examine differences by $\mathrm{SO}_{2}$ response groups and medication categories. A linear regression model (\% change in $\mathrm{FEV}_{1}=$ vitamin $\mathrm{E}+$ vitamin $\mathrm{C}+\beta$-carotene+lycopene+constant) was used to test the hypothesis that $\mathrm{SO}_{2}$ sensitivity, measured by change in $\mathrm{FEV}_{1}$, is associated with plasma antioxidant concentrations. As plasma cholesterol, in the case of vitamin $\mathrm{E}$, and HDL, in the case of lycopene, account for a substantial proportion of the variance in these two antioxidant nutrients, the model adjusted vitamin $\mathrm{E}$ for cholesterol and lycopene for HDL cholesterol.

\section{Results}

Based on data on use of medication from the questionnaire, subjects were divided into four groups that closely match the guidelines for the diagnosis and management of asthma. ${ }^{21}$ Table 1 shows the medication categories and subject characteristics including age, sex, baseline \% predicted $\mathrm{FEV}_{1}$, baseline $\mathrm{FEV}_{1} / \mathrm{FVC}$ ratio, and the \% change in $\mathrm{FEV}_{1}$ after the $\mathrm{SO}_{2}$ challenge. As seen in table 1, there was an inverse correlation between use of medication category and \% predicted $\mathrm{FEV}_{1} \quad$ (Spearman's $r=-0.40$, $\mathrm{p}=0.003)$.

Percentage changes in measures of pulmonary function among $\mathrm{SO}_{2}$ responders and $\mathrm{SO}_{2}$ non-responders, by medication group, are shown in table 2. The change in $\mathrm{FEV}_{1}$ after $\mathrm{SO}_{2}$ challenge ranged from a small increase $(6 \%)$ to a $44 \%$ decrement. Of the 47 subjects screened, $53 \%$ had a drop in $\mathrm{FEV}_{1} \geqslant 8 \%$ (range $-8 \%$ to $-44 \%)$. The mean drop in $\mathrm{FEF}_{25-75}$ after the $\mathrm{SO}_{2}$ challenge was $-26 \%$ for the $\mathrm{SO}_{2}$ responders and $-7 \%$ for the non-responders $(\mathrm{p}<0.001)$. Likewise the changes in FVC $(-10 \% v-1 \%)$ and PEF $(-15 \%, v-2 \%)$ between the responders and non-responders were significant $(p=0.001$ and $p=0.002$, respectively). The $\mathrm{SO}_{2}$ induced decrements in $\mathrm{FEF}_{25-75}$ and $\mathrm{FEV}_{1}$ were significantly greater $(\mathrm{p}<0.05)$ in subjects who used both bronchodilators and anti-inflammatory medication (group 4), compared with those who rarely used medication (group 1). Those who re- 
Table 2 Pulmonary function changes (mean (SD)\% before-after) by $\mathrm{SO}_{2}$ response and medication group

\begin{tabular}{|c|c|c|c|c|c|}
\hline $\mathrm{SO}_{2}$ Response & $\begin{array}{l}\text { Medication } \\
\text { category }(n)\end{array}$ & $F E V_{1}$ & $F V C$ & $F E F_{25-75}$ & $P E F$ \\
\hline \multicolumn{6}{|l|}{ Yes: } \\
\hline 1 & 3 & $-9.2(1.6)$ & $-7.7(3.5)$ & $-16.5(3.6)$ & $-8.2(4.7)$ \\
\hline 2 & 8 & $-12.4(2.9)$ & $-3.9(5.9)$ & $-27.6(7.4)$ & $-9.3(13.1)$ \\
\hline 3 & 8 & $-19.4(13.2)$ & $-12.9(15.7)$ & $-21.1(18.3)$ & $-18.6(17.7)$ \\
\hline 4 & 6 & $-24.7(13.0)$ & $-14.6(10.4)$ & $-36.6(17.1)$ & $-20.9(25.7)$ \\
\hline Group mean & & $-17.2(10.9)$ & $-9.8(11.2)$ & $-26.4(14.9)$ & $-15.0(17.6)$ \\
\hline \multicolumn{6}{|l|}{ No: } \\
\hline 1 & 8 & $-1.3(3.5)$ & $-0.09(0.8)$ & $-5.4(7.6)$ & $0.2(5.8)$ \\
\hline 2 & 7 & $-2.5(3.6)$ & $-0.6(2.2)$ & $-10.3(5.2)$ & $-4.3(4.1)$ \\
\hline 3 & 4 & $-1.1(2.5)$ & $-1.8(3.1)$ & $-1.2(5.2)$ & $-3.4(6.7)$ \\
\hline 4 & 3 & $-3.3(5.5)$ & $-1.7(4.3)$ & $-11.7(21.5)$ & $-4.2(11.4)$ \\
\hline Group mean & & $-1.9(3.5)$ & $-0.8(2.3)$ & $-7.1(9.4)$ & $-2.5(6.3)$ \\
\hline Total & 47 & $-10.0(11.3)$ & $-5.6(9.4)$ & $-17.3(15.9)$ & $-9.1(14.8)$ \\
\hline
\end{tabular}

sponded to $\mathrm{SO}_{2}$ rated lower respiratory symptoms significantly higher than those who did not respond $(\mathrm{p}<0.05)$ after the $\mathrm{SO}_{2}$ challenge (data not shown); this was not the case for upper respiratory or other symptoms.

Blood samples from 38 subjects were obtained for analysis. All correlations discussed were controlled for age, race, and sex. Three plasma variables were correlated with pulmonary function indices before $\mathrm{SO}_{2}$ challenge. There was a significant inverse association between plasma $\beta$-carotene and $\mathrm{FEV}_{1} / \mathrm{FVC} \%$ $(r=-0.40, \mathrm{p}=0.02)$ and $\mathrm{FEV}_{1}$ before challenge $(r=-0.34, \mathrm{p}<0.05)$. Concentrations of HDLs were positively associated with $\mathrm{FEV}_{1} \%$ of predicted $(r=0.35, \mathrm{p}=0.04)$. Plasma ascorbate was inversely associated with PEF before challenge $(r=-0.33, \mathrm{p}<0.05)$.

Mean plasma nutrient concentrations between those who did and did not respond to $\mathrm{SO}_{2}$ are shown in table 3. Although concentrations of plasma nutrients among subjects were normally distributed, the range of values among $\mathrm{SO}_{2}$ responders was often at the low end of the distribution. For example, retinol ranged from 220 to $722 \mu \mathrm{g} / 1$ in those who responded (mean (SEM) 508 (27) $\mu \mathrm{g} / \mathrm{l}$ ) and from 318 to 808 in those who did not respond (mean (SEM) 537 (35) $\mu \mathrm{g} / \mathrm{l})$. Similarly, the values for ascorbate in responders ranged from 0.19 to 1.83 (mean (SEM) $0.99(0.09)$ ) $\mathrm{mg} / \mathrm{dl}$ and $0.52-1.85$ (mean (SEM) $1.18(0.08)) \mathrm{mg} / \mathrm{dl}$ in the non-responders. A value of $<0.2 \mathrm{mg} / \mathrm{dl}$ for plasma ascorbate is considered deficient, 0.2 0.4 is marginal, and $>0.4$, adequate. ${ }^{22}$ Plasma concentrations of $\alpha$-tocopherol were lower in responders than non-responders; however, $\beta$-carotene concentrations were higher in the responders.

Table 3 Screening plasma values (mean (SEM)) by $\mathrm{SO}_{2}$ response

\begin{tabular}{|c|c|c|}
\hline Plasma nutrient & $\begin{array}{l}\mathrm{SO}_{2} \text { responder } \\
(n=22)\end{array}$ & $\begin{array}{l}\mathrm{SO}_{2} \text { non-responder } \\
(n=16)\end{array}$ \\
\hline $\begin{array}{l}\text { Plasma ascorbate } \\
(\mathrm{mg} / \mathrm{dl})\end{array}$ & $0.99(0.09)$ & $1.18(0.08)$ \\
\hline$\alpha$-Tocopherol (mg/l) & $8.70(0.47)$ & $9.22(2.81)$ \\
\hline Retinol $(\mu \mathrm{g} / \mathrm{l})$ & $508(27)$ & $537(35)$ \\
\hline$\beta$-Carotene $(\mu \mathrm{g} / \mathrm{l})$ & $231.3(62.8)$ & $195.1(33.2)$ \\
\hline Lycopene $(\mu \mathrm{g} / \mathrm{l})$ & $304.8 .38(28.3)$ & $294.1(25.4)$ \\
\hline $\begin{array}{l}\text { Total cholesterol } \\
(\mathrm{mg} / \mathrm{dl})\end{array}$ & $161.0(6.2)$ & $182.4(9.1)$ \\
\hline $\begin{array}{l}\text { HDL cholesterol } \\
(\mathrm{mg} / \mathrm{dl})\end{array}$ & $52.3(3.0)$ & $48.2(4.1)$ \\
\hline $\begin{array}{l}\text { LDL cholesterol } \\
(\mathrm{mg} / \mathrm{dl})\end{array}$ & $85.2(5.4)$ & $106(6.1)$ \\
\hline Triglycerides & $117.6(14.8)$ & $144.1(16.7)$ \\
\hline
\end{tabular}

Results of plasma lipid assays showed that mean LDL cholesterol was significantly lower in the responders $(\mathrm{p}=0.02)$. Mean total cholesterol concentrations were lower among nonresponders than among responders $(161 \mathrm{mg} / \mathrm{dl}$ $v 182 \mathrm{mg} / \mathrm{dl} ; \mathrm{p}<0.05)$. Concentrations of HDL were inversely correlated with change in $\mathrm{FEF}_{25-75}(r=0.38, \mathrm{p}=0.02)$ after $\mathrm{SO}_{2}$ challenge; associations with changes in other pulmonary function measures $\left(\mathrm{FEV}_{1} \quad(r=0.08)\right.$, FVC $(r=0.30)$, PEF $(r=-0.07))$ were not significant.

A linear regression model applied for representative plasma antioxidants (vitamin $\mathrm{E}$, vitamin $C$, vitamin $A, \beta$-carotene, lycopene) tested the hypothesis that $\mathrm{SO}_{2}$ sensitivity, measured by pulmonary function changes in $\mathrm{FEV}_{1}$ in these subjects $(\mathrm{n}=38)$, was associated with antioxidant concentrations. None of the associations was significant.

\section{Discussion}

Epidemiological studies have shown a relation between dietary concentrations of vitamin C and pulmonary function as described earlier. ${ }^{7-10}$ However, we found no significant association between plasma concentrations of ascorbate and baseline pulmonary function values in the 38 subjects in this study for whom there were blood samples. We did not have data on diet from the questionnaire on these subjects. The blood samples were not taken after fasting and that may have influenced the outcome; also, a single measurement is often not a good indication of long term values. This study used plasma nutrient concentrations because obtaining epithelial lung fluid concentrations was beyond our scope. However, positive correlations between lung tissue and serum concentrations of $\beta$-carotene, $\alpha$-tocopherol, and total carotenoids (but not retinol) have been found, ${ }^{23}$ adding credence to the concept of use of plasma antioxidant concentrations as a surrogate for lung tissue concentrations, although more research is needed in this area. The people who responded to $\mathrm{SO}_{2}$ in this study participated in a double blind cross over study of the effects of antioxidant dietary supplementation on ozone induced bronchoconstriction. The response to ozone was found to be less after the combined vitamin $\mathrm{C}$ and $\mathrm{E}$ regimen compared with placebo ${ }^{24}$ again indicating a positive correlation between plasma antioxidant concentrations and lung function.

The plasma lipid profile results in this study indicated some differences relating to $\mathrm{SO}_{2}$ response. The lower concentrations of total cholesterol and LDL cholesterol among people who did not respond to $\mathrm{SO}_{2}$, and the inverse association between HDL cholesterol concentrations and change in $\mathrm{FEF}_{25-75}$ after exposure to $\mathrm{SO}_{2}$, may be indirectly explained by the fact that patients with more severe asthma are less likely to exercise regularly, and thus may have a more unfavourable lipid profile. Also, there is evidence that diet may influence severity of asthma, or at least bronchial hyperresponsiveness. ${ }^{25}$ Subjects consuming more dietary fats might also eat fewer fruits and vegetables containing antioxidants and micronutrients that seem to have a protective effect in the lung. ${ }^{7-13}$ 
There was a diverse response among adult subjects with predominantly mild intermittent to mild persistent asthma to the $\mathrm{SO}_{2}$ challenge test. Slightly more than half (53\%) of the young adults reacted to clinically relevant concentrations of $\mathrm{SO}_{2}$. Although use of medication was inversely related to changes in pulmonary function after $\mathrm{SO}_{2}$, severity of asthma defined by medication category was not a perfect predictor of $\mathrm{SO}_{2}$ sensitivity. People who did not respond were represented in each medication category: eight of 11 subjects in category 1 ; seven of 15 in category 2 ; four of 12 in category 3 ; and three of nine in category 4 . Neither \% predicted $\mathrm{FEV}_{1}$ nor the $\mathrm{FEV}_{1} / \mathrm{FVC}$ ratio predicted sensitivity to $\mathrm{SO}_{2}$. The magnitude of ratings on the symptom rating scale at baseline was not associated with sensitivity, although the symptom ratings after $\mathrm{SO}_{2}$ challenge were significantly associated with the \% change in $\mathrm{FEV}_{1}$. This association indicates that the pulmonary function changes in this study are clinically relevant. The large decrements in $\mathrm{FEV}_{1}$ after $\mathrm{SO}_{2}$ challenge among the subjects in categories 3 and $4(>25 \%, n=6)$, would result in stopping activity by most people. The inability of severity of asthma to serve as an indicator for sensitivity to $\mathrm{SO}_{2}$ agrees with a recent epidemiological study which found that severity of asthma was not related to air pollutant response. ${ }^{26}$

As severity of asthma among subjects in this study was based on reported use of medication, we acknowledge the potential for misclassification. When using medication as a surrogate for severity, an optimal treatment regimen is assumed; compliance with prescribed medications is also a potentially problematic underlying assumption. Subjects were required to withhold medications for 6-12 hours before screening visits, however, there is the possibility of an interaction between $\mathrm{SO}_{2}$ and medication in the subjects on regular anti-inflammatory treatment.

The $\mathrm{SO}_{2}$ concentration in this study $(0.5$ ppm) and exposure conditions (10 minutes, 2 $\mathrm{mph}, 10 \%$ grade on treadmill) are comparable with moderate activity during increased ambient concentrations of $\mathrm{SO}_{2}$ and to certain workplace conditions. This concentration of $\mathrm{SO}_{2}$ is found in community air for brief periods and would not result in failure to meet the present United States national standards of ambient air quality for $\mathrm{SO}_{2}$, which is $0.14 \mathrm{ppm}$ for a 24 hour average and $0.03 \mathrm{ppm}$ for an annual average. The Environmental Protection Agency has considered setting a short term standard for $\mathrm{SO}_{2}$ explicitly to protect people with asthma from brief, increased concentrations of $\mathrm{SO}_{2}$. The Puget Sound Air Pollution Control Agency governing Seattle, Washington has set short term standards for $\mathrm{SO}_{2}$ : a 1 hour average of $0.40 \mathrm{ppm}$, never to be exceeded; a 1 hour average of $0.25 \mathrm{ppm}$ not to be exceeded more than twice within 7 days; and a 3 hour average of $0.10 \mathrm{ppm}$, not to be exceeded more than once a year. The data in this study support the need for short term $\mathrm{SO}_{2}$ standards to protect people with asthma. Further research is needed to evaluate the association between diet, plasma antioxidants, and sensitivity to air pollutants.

We acknowledge the following people for their contributions to this study: the study subjects, Kimberly Murphy for excellent phlebotomy and technical assistance, Gary Norris for invaluable technical support, Robyn Perez for clerical assistance, and Drs Daniell, Darowalla, Drachman, Jorgensen, Linden, McCarty, Robinson, Rosenfeld, Sechena, and Takaro for medical superviRobinson, Rosenfeld, Sechena, and Takaro for medical supervi-
sion. This research was funded in part by NIEHS 1 P 30 ES07033; Roche Vitamins; UW Royalty Fund and NIH CNRU ES07033; Roc
DK35816.

1 United States Environmental Protection Agency. Air quality criteria for particulate matter and sulfur oxides. Washington, criteria for particulate matter and sulfur oxides.

2 United States Department of Health and Human Services. Toxicological profile for sulfur dioxide. Atlanta, GA: USDHHS, Agency for Toxic Substances Disease Registry, 1998:87.

3 Koenig JQ, Pierson WE. Pulmonary effects of inhaled sulfur dioxide in atopic adolescent subjects: a review. In: R Frank, JJ O'Neil, MJ Utell, et al, eds. Inhalation toxicology of air pollution: clinical research considerations. Philadelphia: American Society for Testing and Materials, 1986:85-91.

4 Horstman DH, Folinsbee LJ. Sulfur dioxide-induced bronchoconstriction in asthmatics exposed for short durations under controlled conditions: a selected review. In: Utell MJ, Frank R, eds. Susceptibility to inhaled pollutants. Philadelphia: American Society for Testing and Materials, 1989.

5 Koenig JQ. Atmospheric pollutants: sulfur dioxide and particulate matter. In: Barnes PJ, Grunstein MM, Leff AR, et ticulate matter. In: Barnes PJ, Grunstein MM, Leff AR, et
al, eds. Asthma. Philadelphia: Lippincott-Raven, 1997: al, eds.

6 Nowak D, Jorres R, Berger J, et al. Airway responsiveness to sulfur dioxide in an adult population sample. Am $\mathcal{F}$ Respir Crit Care Med 1997;156:1151-6.

7 Britton JR, Pavord ID, Richards KA, et al. Dietary antioxidant vitamin intake and lung function in the general population. Am f Respir Crit Care Med 1995;151:1383-7.

8 Soutar A, Seaton A, Brown K. Bronchial reactivity and dietary antioxidants. Thorax 1997;52:166-70.

9 Schwartz J, Weiss ST. Dietary factors and their relationship to respiratory symptoms: NHANES II. Am $\mathcal{F}$ Epidemiol 1990;132:67-76.

10 Schwartz J, Weiss ST. Relationship between dietary vitamin $\mathrm{C}$ intake and pulmonary function in the First National
Health and Nutrition Examination Survey (NHANES I). Am f Clin Nutr 1994;59:110-14.

11 Hatch GE. Asthma, inhaled oxidants, and dietary antioxidants. Am f Clin Nutr 1995;61 (suppl):625S-30S

12 Greene LS. Asthma and oxidant stress: nutritional, environmental, and genetic risk factors. $\mathcal{f}$ Am Coll Nutr 1995;14:317-24.

13 Troisi RJ, Willett WC, Weiss ST, et al. A prospective study of diet and adult-onset asthma. Am $\mathcal{F}$ Respir Crit Care Med 1995;151:1401-8.

14 Kardinaal AFM, van't Veer P, Brants HAM, et al. Relations between antioxidant vitamins in adipose tissue, plasma and diet. Am F Epidemiol 1995;141:440-50.

15 Kelly FJ, Mudway IS, Blomberg A, et al. Impact of dietary antioxidant supplements on airways epithelial lining fluid (ELF) antioxidant status. Am F Respir Crit Care Med 1998; 157:A196.

16 Koenig JQ, Pierson WE, Horike $\mathrm{M}$, et al. Effects of $\mathrm{SO}_{2}$ plus $\mathrm{NaCl}$ aerosol combined with moderate exercise on pulmonary function in asthmatic adolescents. Environ Res 1981;25:340-8.

17 Rondinelli RCA, Koenig JQ, Marshall SG. The effects of sulfur dioxide on pulmonary function in healthy nonsmoking male subjects aged 55 years and older. Am Ind Hyg Assoc F 1987; 48:299-303.

18 Tulley RT. New enzymatic method for vitamin C in plasma on CX5. Clin Chem 1992;38:1070.

19 Craft NE, Wise SA, Sores JH. Optimization of an isocratic high performance liquid chromatographic separation of carotenoids. F Chromatography 1992;589:171-6.

20 Bierri JG, Tolliver TJ, Catignani GL. Simultaneous determination of $\alpha$-tocopherol and retinol in plasma or red determination of $\alpha$-tocopherol and retinol in plasma or red
cells by high performance liquid chromatography. $A m \mathcal{F}$ cells by high performance
Clin Nutr 1979;32:2143-9.

21 National Heart Lung and Blood Institute. Guidelines for the diagnosis and management of asthma. Bethesda, MD: NIHLB, 1997. (NIH Publication No 97-4041A.)

22 Simko MD, Cowell C, Gilbride JA. Nutrition assessment. Rockville, MD: Aspen, 1984;165-6.

23 Redlich CA, Grauer JN, van Bennekum AM, et al. Characterization of carotenoid, vitamin A and $\alpha$-tocopherol levels in human lung tissue and pulmonary macrophages. $A m \mathcal{F}$ Respir Crit Care Med 1996;154:1436-43.

24 Trenga CA, Williams PV, Koenig JQ. Dietary antioxidants attenuate ozone-induced bronchial hyperresponsiveness (BHR) in asthmatic adults. Am $\mathcal{F}$ Respir Crit Care Med 1997;155:A732.

25 Black PN, Sharpe S. Dietary fat and asthma: Is there a connection? Eur Respir F 1997;10:6-12.

26 Hiltermann TJN, Stolk J, van der Zee SC, et al. Asthma severity and susceptibility to air pollution. Eur Respir $\mathcal{f}$ 1998;11:686-93. 